\title{
EI Derecho y el decorum: el dilema ético y estético de la retórica jurídica
}

Law and decorum: the ethical and aesthetic dilemma of legal rhetoric

\author{
Dr. Juan Ramón RODRÍGUEZ LLAMOSÍ \\ Magistrado. \\ Master universitario en Humanidades.
}

\begin{abstract}
"SÓCRATES.- [...] Dime tú, en los tribunales, ¿qué hacen los pleiteantes?, ¿no se oponen, en realidad, con palabras? ¿O qué diríamos?

FEDRO.- Diríamos eso mismo.

SÓCRATES.- ¿Acerca de lo justo y de lo injusto?

FEDRO.- Sí.

SÓCRATES.- Por consiguiente, el que hace esto con arte, hará que lo mismo, y ante las mismas personas, aparezca unas veces como justo y, cuando quiera, como injusto".
\end{abstract}

PLATÓN, Fedro (261c)

Resumen: El presente trabajo analiza de qué manera el jurista puede emplear la retórica jurídica como arte (estética) y como virtud (ética) para que resplandezca la verdad y, con ella, la Justicia, sin afectar el decoro, entendido como lo adecuado, lo apropiado. Para ello se examinan los límites clásicos de la retórica jurídica y los planteamientos actuales de la nueva retórica, con una referencia a la estrategia judicial de ruptura.

Abstract: This essay analyzes how the jurist can use legal rhetoric as art (aesthetics) and as virtue (ethics) to shine the truth and, with it, the Justice, without affecting the decorum, understood as the appropriate. To this end we study the classic limits of legal rhetoric and the modern studies about new rhetoric, with a reference to the judicial strategy of rupture.

Palabras clave: Derecho, retórica, ética, estética, estrategia.

Keywords: Law, rhetoric, ethics, aesthetics, strategy. 
Sumario:

I. Presentación.

II. Los límites de la retórica clásica.

III. La nueva retórica y la estrategia judicial de ruptura.

IV. El dilema de la retórica jurídica.

Recibido: septiembre de 2019.

Aceptado: noviembre de 2019. 


\section{PRESENTACIÓN}

Al final de La Ilíada, en venganza por la muerte de su amado amigo Patroclo, Aquiles da muerte a Héctor y ultraja su cadáver enganchando su cuerpo a su carro y dando siete vueltas alrededor de las murallas de Troya para mutilarlo ante la vista de Príamo, su desesperado padre, a quien niega entregárselo para que pueda darle una digna sepultura ${ }^{1}$.

Príamo, padre de Héctor y rey de Troya, es un hombre anciano y cansado de la guerra, de sus constantes tragedias y de la pérdida de todo lo que ama, especialmente de sus hijos, que han sido abatidos a manos de los aqueos: Troilo (asesinado por Aquiles en una emboscada), Héleno (secuestrado para que usara sus dotes de adivino en favor de los ejércitos griegos) y Casandra (sometida a esclavitud). Está abrumado por tanto dolor y se siente predestinado (a sucumbir. La muerte de Héctor no le deja más recurso que la súplica para que le devuelvan el cuerpo de su hijo.

Disfrazado como un campesino, Príamo sale de Troya conduciendo un carromato y se dirige al lugar donde los griegos tenían su asentamiento fortificado. Gracias a la ayuda del dios Hermes, que adormeció a los guardias que vigilaban las puertas, logra llegar a la tienda de campaña de Aquiles y, una vez ante el héroe, se abraza a sus rodillas y le suplica que le permita dar a Héctor una digna sepultura. Lo patético del discurso de Príamo, la fuerza de sus palabras, lleva a Aquiles a un abismo moral en el que se tambalea lo moral, lo humano. Aparece el conflicto ético. Aquiles se apiada del anciano y le entrega el cuerpo de Héctor con el que Príamo regresa a Troya para poder realizar unos funerales apropiados ${ }^{2}$.

${ }^{1}$ Sabido es que en la Grecia clásica el entierro de los difuntos era una creencia familiar muy arraigada. Se creía que los espíritus de los antepasados eran una especie de divinidades a las que se debía rendir culto de forma periódica. Los griegos tenían, pues, el deber de enterrar a sus muertos, ya que las almas de los que no recibían sepultura ni rito funerario alguno estaban condenadas a vagar eternamente y a perseguir a sus parientes por haber descuidado el cumplimiento de los preceptos religiosos con los difuntos. Esta norma no se respetaba con los ladrones de templos, con los suicidas, ni con los delincuentes ajusticiados.

${ }^{2}$ HOMERO, Iliada, XVIII, 497-508. 
La Ilíada es un excelente ejemplo de la importancia de la palabra persuasiva de los líderes. Para Aquiles, tan importante es aprender discursos públicos como desarrollar sus habilidades como guerrero ${ }^{3}$. Odiseo, que posee una palabra contundente, lo que le confiere el liderazgo, se enfrenta con Tersites acusándolo de ser un "orador sin juicio". . Nestor se caracteriza porque posee una lengua más dulce que la miel y la palabra fluye dulcemente ${ }^{5}$. Y, en fin, a lo largo de toda la epopeya griega, Homero ofrece en todos y cada uno de los hexámetros de que se compone el poema la importancia de la palabra, del estilo y de la persuasión desde el principio hasta el final pues, muerto Aquiles, se discute quien ha de poseer las armas del Pélida, y Ayante, el más fuerte de los guerreros griegos cree que serán suyas. Sin embargo, el astuto Ulises, gracias a sus dotes persuasivas, consigue hacerse con ellas. Y, nuevamente, aparece la persuasión como modo de vencer ${ }^{6}$.

De eso trata el presente trabajo: del uso lícito de las habilidades oratorias, de quien domina el uso de las palabras en el Derecho para persuadir, de la frágil línea entre persuasión y mentira. Es el difícil equilibrio entre ética y estética, entre virtud y arte en la retórica jurídica donde no sólo importa lo que se dice, sino como se dice, aunque no siempre lo que se dice bellamente es correcto éticamente. $\mathrm{Y}$ es que la retórica jurídica tiene un cierto carácter de arte y de técnica amoral al mismo tiempo. Quizás por eso, cuando en el año 1577 el Veronés realizó aquella bella alegoría de la retórica para decorar la Sala del Colegio del Palacio Ducal de Verona representa a la joven Aracne como una noble veneciana cubierta con pesados y suntuosos ropajes sujetando entre sus manos una tela de araña que simboliza, precisamente, la retórica como el arte de embelesar al público con palabras. Lo mismo que la araña teje su tela para cazar a sus presas, así el orador debe usar la persuasión para conseguir los beneficios propios a su fin particular ${ }^{7}$.

\footnotetext{
3 Ídem, IX, 442-443.

4 Ídem, II, 246.

5 Ídem, I, 249.

${ }^{6}$ No olvidemos tampoco que el episodio de la locura que arrebata a Áyax al perder la armadura de Aquiles cuando ya había fallecido y le había sido otorgada a Odiseo, tema de la conocida tragedia de Sófocles, es con toda seguridad uno de los primeros en nuestra tradición cultural en los que se establece la preferencia hacia quien domina el uso de las palabras.

${ }^{7}$ La historia de Aracne es un claro ejemplo del peligro que supone retar a los dioses. Aracne era una joven campesina que destacaba por sus bellos tapices y que afirmaba ser mejor que Minerva, la tejedora de los dioses. Minerva retó a Aracne en la elaboración de un tapiz. Las dos se pusieron manos a la obra resultando dos bellos tapices sin diferencias apreciables. Minerva rasgó, encolerizada, la tela de Aracne y golpeó a la joven. Aracne se ahorcó y la diosa, arrepentida, la transformó en araña para que conservara su destreza en tejer.
} 


\section{LOS LÍMITES DE LA RETÓRICA CLÁSICA}

La retórica es un arte. Y una adecuada retórica constituye el fundamento de cualquier discurso filosófico, teológico o jurídico. $\mathrm{O}$, a la inversa, no se puede construir éste sin una adecuada retórica ${ }^{8}$. Sin embargo, en su modalidad jurídica, la retórica no es un arte sencillo porque afecta a lo moral, a lo ético. Cada día, cientos de abogados deben moverse en esa frágil tela de araña de la persuasión para convencer, para postular la Justicia, para defender los intereses y los derechos de los particulares frente a otro o frente a la colectividad, o contra el mismo Estado, valiéndose para ello de la palabra bien argumentada. Por eso, una buena retórica jurídica exige, no sólo buenas fuentes de conocimiento legal y jurisprudencial, sino la exposición ponderada de la palabra, de la argumentación, expuesta en conciencia, con honestidad, aún en muchas situaciones conflictivas de riesgo e incomprensión y de ruptura.

El estremecedor diálogo entre Antífona y Creonte en defensa de la dignidad del hombre, expresado magistralmente en la conocida tragedia de Sófocles ${ }^{9}$,

${ }^{8}$ El mismo san Agustín decía que, en su juventud, practicaba con intensidad la retórica en el foro de Cartago poniendo a prueba sus conocimientos. Vid. SAN AGUSTÍN, Las Confesiones, Libro III, 6.

${ }^{9}$ La tragedia de Antígona, magistralmente concebida por Sófocles en Atenas 441 años a. de Xto. plantea la cuestión de si deben obedecerse las leyes humanas o las divinas, si son más importantes las leyes escritas que las no escritas. Dicha tragedia comienza en el momento en que Creonte manda honrar pomposamente el cadáver de Etéocles y prohíbe enterrar el cadáver de Polínice, condenado a ser pasto de animales carroñeros, por traición a Tebas, su patria. Antífona, paradigma de la piedad (eusébeia), del culto a la unidad familiar, siente la necesidad de dar sepultura a su hermano que se ha sublevado contra la patria, pues el enterramiento es, como sabemos (vid. nota 1), el modo de devolver el muerto a los ancestros, al ámbito de su familia. Por la noche, aprovechando un descuido de la guardia, cubre de tierra el cadáver, pero es sorprendida y llevada ante el rey. La única razón que Antígona aduce en su favor para defenderse es la inviolabilidad de las leyes divinas, las cuales cimientan el sentido del individuo en comunidad. La validez de tales leyes es universal, se extiende desde el ámbito de los dioses olímpicos (con Zeus a la cabeza) hasta la oscura región del Hades. No hay sitio en el Universo donde sean una excepción tales "leyes no escritas". El núcleo de la tragedia, ya en pleno dialogo entre Creonte y Antígona, contiene la arenga de ésta: "No era Zeus quien me imponía tales órdenes; ni tales leyes han sido dictadas a los hombres por la Justicia que tiene su trono con los dioses de las profundidades, ni crei que tus bandos habian de tener tanta fuerza que habias tú, mortal, de prevalecer por encima de las leyes no escritas e inquebrantables de los dioses. Que no son de hoy ni de ayer, viven siempre y nadie sabe cuándo aparecieron. No iba yo a incurrir en la ira de los dioses violando esas leyes por temor a caprichos de hombre alguno". Vid SÓFOCLES, Antifona, v. 450-456. La tragedia griega ha sido un importante referente de reflexión filosófica para el pensamiento contemporáneo, principalmente de filosofía moral, jurídica y política, siendo innumerables los autores y las obras consagradas a analizar y valorar el papel y el alcance de la Antígona de Sófocles. Ya Hegel se refirió a ella en su Estética (II, 2, I), o en su Filosofía del Derecho (Parte Tercera, sección primera, 166), describiéndola como un conflicto entre dos derechos, el familiar y el estatal, igualmente válidos. De hecho, Hegel llegó a plantearse el 
es reproducido en multitud de ocasiones ante los Tribunales de Justicia por los abogados que, en conciencia, se resisten a aceptar la sumisión incondicional en determinadas situaciones porque, como decía Jaspers, la atmósfera de sumisión supone de por sí una culpabilidad colectiva ${ }^{10}$. Y es que la retórica jurídica supone un uso adecuado del lenguaje legal valiéndose de la estrategia, del argumento persuasivo, en aras a obtener un fin procesal, pero ¿existen límites?

Los tratadistas de retórica de la Antigüedad grecorromana desmenuzaron esta disciplina de forma ejemplar y exhaustiva, cuidando por igual la parte argumentativa como la estilística, de tal manera que el conocimiento y el dominio del arte de la elocuencia se consideraba esencial. Por esa razón, surgieron en dicha época histórica obras tan relevantes como la Retórica de Aristóteles, De inventione, De óptimo genere oratorum, Orator, y Brutus de Cicerón y la Institutio oratoria de Quintiliano, sin olvidar la Retórica a Alejandro adscrita a Anaxímenes de Lámpsaco, la Rhetorica ad Herennium de Cornificio, el De sublimitate del Pseudo-Longino, o la labor de Hermágoras de Temnos, el rétor más importante del período helenístico (a mediados del s. II a. Xto.) ni la de Hermógenes de Tarso (del s. II d. Xto.).

Ya en el "Encomio de Helena", Gorgias de Leontinos, el célebre orador y sofista de los siglos V y IV a. Xto, decía:

“...la palabra es un gran soberano que, con un cuerpo pequeñisimo y sumamente invisible, consigue efectos realmente divinos; puede ya

\footnotetext{
sentido ético de la mujer en la familia que representaba la obra en su Fenomenología del Espiritu (concretamente los dos primeros títulos completos de la penúltima parte dedicados al espíritu o Geist). E, incluso, no falta quien se identifique con Antígona, pero también los hay que piensan que la tragedia, a pesar de su nombre, es la tragedia de Creonte o que éste es el centro de atención del poeta. Vid. LUCAS DE DIOS, J. M., "Introducción" a su traducción de Sófocles. Áyax, Las Traquinias, Antígona y Edipo Rey, Madrid 1988, p. 43. E, incluso, quien expresa claras simpatías políticas por Creonte. Vid. TOVAR, A., "Antígona y el tirano o la inteligencia y la política", en Escorial (1942), recogido en su libro Ensayos y peregrinaciones, Madrid 1960, pp. 1 y ss. Ya George Steiner nos había puesto al tanto de la variedad de interpretaciones y lecturas que se han hecho de Antígona, insistiendo, por su parte, en que no es un texto cualquiera, sino uno de los hechos perdurables y canónicos en la historia de nuestra conciencia filosófica, literaria y política. Vid. G. STEINER, Antifonas: la travesía de un mito universal por la historia de Occidente, trad. de Alberto L. Bixio, Barcelona 2009.

10 Jaspers describía así la complicidad de los alemanes: "El terror produjo el sorprendente fenómeno de que el pueblo alemán participara en los crímenes del Führer. Los sometidos se convirtieron en cómplices. Desde luego, sólo en una medida limitada pero de forma tal que personas de las cuales uno nunca lo hubiera esperado, padres de familia, ciudadanos diligentes que concienzudamente practicaban su profesión, asesinaron también concienzudamente y, siguiendo órdenes, cometieron otros crímenes en los campos de concentración”. Vid. JASPERS, K., El problema de la culpa, Barcelona 1998, p. 32.
} 
eliminar el miedo, ya suprimir el dolor, ya infundir alegría, ya aumentar la compasión",11.

Por eso, equiparaba la retórica con la medicina de tal modo que, así como el médico prescribe fármacos para restablecer la salud del cuerpo, el orador da discursos para alcanzar la salud del alma:

“Guardan la misma relación la potencia de la palabra respecto de la situación del alma que la prescripción de las medicinas respecto de la naturaleza del cuerpo. Porque asi como unas medicinas expulsan del cuerpo unos humores y otras otros, y unas hacen cesar la enfermedad y otras la vida, asi también, de las palabras, unas producen dolor, otras deleite, unas asustan, otras infunden ánimo a los oyentes, otras, con cierta persuasión perversa, envenenan el alma y la hechizan" ${ }^{\prime 2}$.

También Protágoras de Abdera, sofista del siglo V a Xto., en la conocida apología que le atribuye Platón en el Teeteto, establece un paralelismo entre el médico y el sofista:

“...en la educación hay que hacer una trasformación desde una condición a otra que sea mejor. El médico hace esta transformación con remedios; el sofista, en cambio, con argumentos" $" 13$.

Desde luego, toda la retórica se articula en torno a la efectividad de la persuasión y a los medios que hay que emplear para conseguirlo. Es la adecuación entre fondo y forma, entre estilo y comunicación y varía según se utilice ante los tribunales de justicia (oratoria judicial), en las asambleas (oratoria deliberativa) y en las reuniones festivas o las ceremonias conmemorativas (oratoria epidíctica).

Así entendida la retórica antigua como el arte de emplear atinadamente la palabra para lograr la persuasión hablando en público o mediante los escritos, las reglas de la composición oral o escrita variaron muy poco desde sus inicios hasta el siglo XIX, y se distribuían en cinco capítulos correspondientes a las cinco partes que, en un orden lógico, se establecían dentro del proceso de la elaboración y la ejecución del discurso por parte del orador: invención (hallazgo del entramado argumental que el orador va a esgrimir); disposición (organización en una estructura sólida y bien ordenada del material); elocución (plasmación

\footnotetext{
${ }^{11}$ GORGIAS, "Encomio de Helena", recogido en Los sofistas: testimonios y fragmentos, traducción de José Solana Dueso, Madrid 2013, pp. 192-199.

${ }^{12}$ Ibídem, pp. 199.

${ }^{13}$ PLATÓN, Teeteto, 167 a.
} 
del estilo o lenguaje elegido del texto del discurso); memoria (palabras memorizadas que van a ser pronunciadas); y pronunciación (ejecución del discurso siguiendo una técnica determinada y bien precisa).

Una de las primeras formulaciones a los límites de la retórica clásica la encontramos, precisamente, en la Retórica de Aristóteles, al principio del libro III $^{14}$. Antes de entrar en el tema de la expresión, de la elocutio, de la lexis, expone la necesidad de poner ciertos límites ${ }^{15}$. Dice así:

"Porque lo justo y nada más que ello es lo que hay que buscar en el discurso, antes que el no disgustar o el regocijar al auditorio, y lo justo es ciertamente debatir acerca de los hechos mismos, de suerte que todo lo que queda fuera de la demostración es superfluo. Con todo, al mismo tiempo es potencialmente importante, como ya hemos dicho, a causa de los vicios del auditorio. Y, por lo tanto, lo que concierne a la expresión es también -siquiera sea en una pequeña medida- necesario en toda enseñanza, puesto que para las demostraciones hay diferencias en expresarse de un modo u otro" ${ }^{\prime 6}$.

Lo que Aristóteles formula es una regla esencial del decoro y es que la lexis ha de ser adecuada, apropiada. Lo que evidencia el texto es una preocupación por lo adecuado, por lo aptum como eje de la retórica. La raíz etimológica de la palabra decoro se halla en la lengua latina: decorum. El decoro se refiere a los límites que fijan las normas sociales sobre aquello que debe ser considerado como correcto o adecuado en una determinada situación. Quien no actúa según estos preceptos, no tiene decoro. Así, el decoro puede referirse al respeto, la honra, el recato o la circunspección; también se vincula a la vestimenta (o a la falta de ella); o al nivel de calidad de vida mínimo que debe tener una persona para mantener su dignidad, es decir, para que ésta no se vea amenazada por la falta de recursos. En todos los casos, el decorum apunta a lo mismo: lo apropiado, lo adecuado. Es un término que enlaza lo estético y lo moral ${ }^{17}$. En este sentido, el decoro es el concepto que más esencialmente define la retórica. Se aplica a lo que hay que decir y a cómo hay que decirlo.

También en Cicerón encontramos la preocupación por lo adecuado, por lo aptum, como noción vertebradora de la retórica. Son varios los pasajes de

\footnotetext{
${ }^{14}$ Vid. ARISTÓTELES, Retórica, 1404 a.

${ }^{15}$ Es en la Retórica, donde Aristóteles distinguía los tres géneros de discursos retóricos: discursos deliberativo (I, 4-8), forense (I, 9) y judicial (I, 10-15).

${ }^{16}$ ARISTÓTELES, Retórica, Libro III (1404 a).

${ }^{17}$ Aristóteles y Cicerón se refieren a este sentido en relación con la retórica en la Ética a Nicómaco (1097 a 4) y en el De officiis $(1,92)$, respectivamente.
} 
sus escritos a los que podríamos acudir, pero nos vamos a referir a su más amplia y monumental obra en este campo: el diálogo De oratore. De todos los personajes que intervienen en este diálogo es Craso quien más se identifica con las posturas que sostendría el propio Cicerón. Y dice:

"Pues al que llamamos inoportuno parece que recibe esa denominación por el hecho de no ser oportuno y esto queda patente a lo largo de nuestra práctica lingüística. Pues quien no ve qué es lo que exige cada ocasión o habla más de la cuenta, o hace ostentación de sí mismo, o no tiene en cuenta la consideración y los intereses de quienes le rodean, o quien, en fin, en algún punto desafina o exagera, ése recibe el nombre de inoportuno" ${ }^{18}$.

Los términos latinos que están detrás de las expresiones oportuno e inoportuno son aptum e ineptus, y lo que Craso sanciona es la falta de adecuación a lo que resulta decoroso no sólo en cuanto al estilo, sino también en cuanto a la actitud del orador. El pasaje más importante al respecto vuelve a estar en boca de Craso cuando dice:

“... veamos ahora qué es lo adecuado, es decir, qué es lo más conveniente en cada discurso. Y, sea como sea, ciertamente está claro que no existe un único tipo de discurso que cuadre con cualquier causa, público, personas o circunstancias; (...). Importa además quiénes son los oyentes, si el senado o el pueblo o los jueces; si son muchos, o pocos, o uno solo y de qué condición; y en cuanto al propio orador, debe tenerse en cuenta cuál es su edad, su trayectoria pública, su prestigio; en cuanto a las circunstancias, si son de paz o de guerra, de premura o de bonanza",19.

Lo que Cicerón señala por boca de Craso es que en la retórica lo fundamental no es tanto las reglas sino qué es lo adecuado. Lo importante no es la técnica, sino el decorum. Y la regla para discernir cuando se conserva el decorum y cuando se quebranta no se enseña, sino que es la experiencia la que la da. En este sentido, está fuera del ars. Las palabras de Craso son esclarecedoras:

"Y así, en este punto no parece que pueda darse ningún consejo (...). A lo largo de todo el discurso, ser capaz de hacer lo que debe hacerse compete a la técnica y dotes naturales del orador, pero saber cuándo hay que hacerlo, a su prudencia ${ }^{\prime 20}$.

\footnotetext{
${ }^{18}$ CICERÓN, De oratore, II, 17.

19 Ídem, III, 210-211.

20 Ídem, III, 212.
} 
Sin embargo, es a Quintiliano a quien, con mayor peso, se debe la armonización entre retórica y moral. Es de sobra conocida su famosa definición del orador como: "vir bonus dicendi peritus" (es decir, el hombre que domina las técnicas oratorias pero además es bueno en el sentido moral ${ }^{21}$. Y a él se debe el tratamiento más completo acerca del decorum en la retórica al que dedica el libro XI de su Instituto oratoria. El libro X concluye con la inventio, la dispositio y la elocutio, y sólo le quedan la memoria y la actio, a los que dedica los capítulos 2 y 3 del Libro XI, pero antes de referirse a ellos dedica el primer capítulo al decorum y advierte que es una cualidad "maxime necessaria", es decir, "la más esencial", porque para que un discurso sea adecuado su éxito va más allá de sus cualidades técnicas ${ }^{22}$.

En todo el capítulo XI, Quintiliano propone una serie de recomendaciones. En primer lugar, la modestia: hay que evitar a toda costa la auto-alabanza porque despierta no sólo el aburrimiento (fastidium) de los oyentes sino también su animadversión. Dice: "Nuestra mente tiene cierta altanería y orgullo natural que no le hacen fácil soportar la idea de alguien superior"23. Se expone uno al ridículo, si no se es consciente de las propias fuerzas y luego no se colman las expectativas que irresponsablemente se habían despertado ${ }^{24}$, aunque no se trata de que no se pueda aludir a los propios $\operatorname{logros}^{25}$. Por tanto, no hay que presumir de las propias dotes, pero hay que mostrar confianza en ellas.

También desaconseja Quintiliano que el orador declare desde el principio haber considerado ya el asunto y haber asumido su defensa por estar convencido de su justicia ${ }^{26}$. Esto supone, según Quintiliano, decidir de antemano por el jurado, lo que no es de agrado, a menos que el orador esté investido de cierta autoridad (por su edad, por su trayectoria personal o por su prestigio), en cuyo caso puede aprovecharse de tal autoridad.

Señala después Quintiliano los rasgos generales de una actio adecuada y establece cómo los posibles estilos de un discurso deben ser apropiados a la

${ }^{21}$ Aunque la expresión se debe a Catón en el siglo II a. de Xto, Quintiliano la hace suya y la aplica como esencia de lo que debe ser un orador en su Instituto Oratoria, en el último de sus libros, en concreto, el duodécimo.

${ }^{22}$ QUINTILIANO, Instituto oratoria, 11, 1, 1.

${ }^{23}$ Ídem, 11, 1, 16-28.

${ }^{24}$ En éste pasaje Quintiliano critica aquellos versos de Cicerón, quizás los peores versos escritos en latín, en los que se elogiaba a sí mismo como salvador de Roma: " $O$ fortunatam natam me consule Romam!".

${ }^{25}$ QUINTILIANO, Instituto oratoria, 11, 1, 22. Como hizo Demóstenes en su famoso discurso Sobre la corona contra los que atacaban a Ctesifonte, o el propio Cicerón en Las Catilinarias, tras haber sido descubierta y reprimida una conjura encabezada por Catilina para dar un golpe de Estado.

${ }^{26}$ Ibídem, 11, 1, 28. 
condición del orador (a su edad, al cargo político que desempeñe, a su formación cultural, etc.). Así, por ejemplo, dice: "A menudo una misma frase resulta en un orador expresión de sinceridad, en otro de ira, de arrogancia en un tercero "27.

Pero para Quintiliano hasta tal punto el concepto de decorum transciende todas las dimensiones de la retórica que considera que éste debe ser el criterio supremo, con lo que se plantea el conflicto entre hacer lo que hay que hacer (es decir, conservar el decorum) o actuar en busca de lo útil, de lo efectivo. En principio, según Quintiliano, ambas cosas deberían coincidir en la mayoría de los casos, pero ante una posible incompatibilidad, hay que sacrificar la efectividad. Es decir, que la persuasión, que para algunos es el fin esencial de la retórica, ha de sacrificarse en aras del deber. Dice: "por encima del criterio de la utilidad ha de estar el de hacer lo que hay que hacer",28.

En este sentido, para Quintiliano, la dignidad del orador está por encima de la persuasión. El ejemplo al que acude es el de Sócrates en el trance de su condena a muerte. Dice que nada hubiera sido más fácil para Sócrates que realizar una autodefensa recurriendo a las técnicas retóricas, adoptando un tono de humildad ante sus jueces y rechazando los cargos de los que se le acusaba ${ }^{29}$. Sin embargo, el precio habría sido excesivo para su dignidad, no habría hecho lo que tenía que hacer y habría quebrantado el decorum.

La última frase de Quintiliano concluye con la importancia de la moral del orador. Dice así:

"Todas éstas eran, Marco Victorio, las reglas con las que me parece puedo contribuir al progreso de la enseñanza de la oratoria; aunque el conocimiento de estas normas resulta ser de poca utilidad a los jóvenes estudiantes, deseo que al menos les induzca a lo que es para mi más importante, la buena voluntad" ${ }^{\prime 30}$.

\section{LA NUEVA RETÓRICA Y LA ESTRATEGIA JUDICIAL DE RUPTURA}

Como hemos señalado en el anterior apartado, la retórica se ha presentado históricamente como un modelo formal de construir los argumentos, como la estructura del discurso y como un conjunto de figuras. En cualquier campo de aplicación, la retórica tiene como fin persuadir y proponer al auditorio un

\footnotetext{
${ }^{27}$ Ibídem, 11, 1, 37.

${ }^{28}$ Ibídem, 11, 1, 9.

${ }^{29}$ Ibídem, 11, 1, 9-11.

${ }^{30}$ Ibídem, 12, 11,31.
} 
modo particular de ver el estado de las cosas. Téngase en cuenta que la retórica no tiene que ver con lo verdadero sino con lo probable. El orador lo que pretende es influir o convencer, mover los afectos del oyente: "delectare" y "movere" son los ejes de su arte.

Por estas razones, las modernas definiciones contemporáneas de la retórica prescinden del estilo y aluden a ella como la construcción de una moderna ciencia general del discurso cuyo fundamento es el arte de presentar argumentos. La nueva retórica, a causa del racionalismo imperante desde mediados del siglo XVII al XIX, reacciona de esta manera contra la reducción de la retórica clásica a una especie de estilística y rechaza el hecho de que esta disciplina se entienda, no como arte o tratado de la persuasión, que es lo que en su origen fue, sino como el arte de presentar argumentos. A esta nueva forma de entender la retórica se la denomina "nueva retórica" y tiene su base en los trabajos contemporáneos de Chaim Perelman ${ }^{31}$.

Lo que Perelman hace es elaborar una serie de estudios encaminados a la renovación de una antigua disciplina filosófica que estuvo olvidada en algunas épocas: la teoría de la argumentación. Sostiene que hay formas de razonamiento más elevadas, las cuales no constituyen propiamente cálculos, ni tampoco pueden ser formuladas como demostraciones, y que pertenecen, por el contrario, a la argumentación, cuyo estudio había sido descuidado, sobre todo en los últimos tres siglos.

Esta "nueva retórica" de Perelman retoma de la retórica antigua el concepto de auditorio en el sentido de que todo el discurso retórico tiene como objeto convencer, persuadir o buscar la adhesión del auditorio a las premisas del orador, sin embargo, propone, en cambio, un auditorio universal, conformado por los hombres normales (también los denomina competentes y razonables), y un auditorio especializado, conformado por hombres que comparten un mismo conocimiento. Estos dos espacios son el escenario de la persuasión. Aunque se mantenga la idea de auditorio tanto en la retórica clásica como en la nueva retórica, lo nuevo radica en que la nueva retórica estudia los mecanismos del discurso y su eficacia práctica (como en el caso del discurso de la disputa judicial), así como los mecanismos internos de la producción textual literaria dado que se trata de establecer las condiciones generales en las que resulta posible construir un discurso persuasivo.

${ }^{31}$ PERELMAN, CH., Tratado de la argumentación: la nueva retórica, Madrid 1989. Perelman mantiene la mutilación histórica de la disciplina y rescata una de sus partes olvidadas como la teoría de la argumentación. Nueva retórica significa la restitución como problema principal de la retórica de uno de sus pilares como lo es la argumentación y deja a un lado la composición y la enunciación. 
En este contexto, debemos hacer referencia a una figura destacada en el mundo de la retórica jurídica. Es el caso del abogado penalista francés Jacques Vergès (1925-2013) $)^{32}$ encargado de la defensa de numerosas casos mediáticos: Tarek Aziz, Klaus Barbie, el terrorista Carles "el Chacel”, el general congolés Norbert Dabira, el Ministro de Costa de Marfil Mohamed Diawara, Khieu Zampan, uno de los tres dirigentes de los Jemeres Rojos juzgados por sus crímenes contra la humanidad, Slobodan Milosevic, Cheyenne Brando (hija del actor Marlon Brando), etc. ${ }^{33}$.

Su importancia no sólo se debe a la defensa de aquellos casos mediáticos, que la tuvo, sino por una destacada obra doctrinal (de más de 30 libros), que llamó la atención de dos filósofos destacados del siglo XX: Jacques Derrida ${ }^{34}$ y Michel Foucault ${ }^{35}$. Ambos dedicaron numerosas páginas a comentar la obra más importante de Vergés titulada: "De la estratégie judiciare" 36.

Lo más relevante de este abogado penalista francés a los efectos de nuestro estudio es el uso de una singular estrategia judicial de la que se valió en aquellos procesos judiciales en los que intervino: la llamada estrategia judicial de ruptura. Según Vergès existen dos tipos de actitudes que un acusado puede adoptar frente a un tribunal: la connivencia o la ruptura. Dice así:

"La distinción fundamental que determina el estilo del proceso penal es la actitud del acusado frente al orden público. Si lo acepta el proceso es posible y constituye un diálogo entre el acusado que se explica y el juez cuyos valores son respetados. Si lo rechaza, el aparato judicial se desintegra, es el proceso de ruptura" ${ }^{\prime 37}$.

${ }^{32}$ Y cuya vida fue llevada al cine. En el año 2007 se estrenó en Francia la película: "L'avocat de la terreur", dirigida por Barbet Schroeder que fue premiada con el premio César al mejor documental del año 2007. Se trata de un documental provocativo sobre la controvertida figura de Jacques Vergès.

${ }^{33}$ En el año 2012 se publicó una tesis doctoral elaborada por Jonathan Widell titulada: "Jacques Vergès, Devil's Advócate, A Psycohistory of Vergès Judicial Strategy” en Faculty of Law, Mac Gill University, Montreal.

${ }^{34}$ Derrida escribió acerca de la estrategia de Vergès en su ensayo "The Force of Law, The Mystical Foundation of Authority" en Cardozo Law Review, Vol. 11 (1999). Puede verse una versión bilingüe en francés e inglés de dicho ensayo en: http://roundtable.kein,org/node/607. También en una entrevista a Derriba sobre Vergès publicada en "Ethics and Politics today" en Negotiations-Interventions and Interviews, 1971-2001, Stanford, Satanford University Press, 2002, p. 308.

${ }^{35}$ Vergès y Foucault fueron en los años 80 miembros de un foro de activistas llamado Defensa Libre que luchaba por la defensa de los presos políticos y a ello se refirió Foucault en su libro Dits et éccits, París 1994, pp. 130-134.

${ }^{36}$ Fue publicada en 1968 en Francia. En España fue publicada en el año 2009 en Barcelona por la editorial Anagrama con el título: "Estrategia judicial en los procesos politicos".

37 VERGÈS, J., Estrategia judicial en los procesos políticos, Barcelona 2009, p. 22. 
Es decir, Jacques Vergès distingue entre la posibilidad o imposibilidad de todo diálogo entre los participantes. Si el acusado acepta el orden público, el proceso constituye un diálogo en el que el juez -cuyos valores son respetadosintenta determinar la responsabilidad del acusado en un hecho que todos coinciden en considerar delictivo. Estos juicios son "de connivencia" y suponen una serie de acuerdos tácitos (la validez del tribunal, de las leyes y de los procedimientos, el sometimiento al veredicto, etc.) y un desacuerdo: la inocencia o culpabilidad del imputado (en algunos casos, la realidad del hecho mismo). Pero si el acusado rechaza el orden público, no reconoce el sistema que lo juzga, el aparato judicial se desintegra; entonces el juicio es "de ruptura" e implica acuerdo acerca de la realidad del hecho y de la culpabilidad del acusado, y desacuerdo en todo lo demás (que el hecho constituya un crimen que deba ser castigado, la legitimidad del tribunal, que el juicio mismo sea una instancia válida, etc.).

El planteamiento de la estrategia judicial de ruptura es, según Vergès, la negación de la autoridad del sistema judicial. Para Jacques Vergès:

"La justicia, tal como la entienden los juristas -la gente más reaccionaria del mundo, según Lenin- y tal y como es administrada, es una justicia de connivencia por la sencilla razón de que toda sociedad que organiza tribunales lo hace a fin de juzgar, según sus normas, los atentados contra su legalidad. Por ello, la posibilidad de una ruptura sorprende siempre a los jueces y numerosos defensores la rechazan; lo más que puede esperarse de ellos es que traten de poner a la sociedad en contradicción con sus principios ${ }^{\prime 38}$.

El caso más famoso que dio origen a la llamada estrategia de ruptura fue el juicio a la terrorista argelina Djemila Bohuired, que se convertiría después en su esposa y madre de sus dos hijos, acusada de participar en el atentado terrorista ocurrido el día 26 de enero de 1957 que provocó cuatro muertos y más de 40 heridos y de almacenar material explosivo para fines terroristas.

El objetivo de Vergès durante el proceso no era convencer a los jueces, sino provocar incidentes y escándalos en la Sala de Vistas para que se hablara del juicio en París, Londres o Bruselas. Para ello, convirtió a la acusada en acusadora impugnando la legitimidad del Tribunal para poder juzgar los hechos y poder presentar de este modo a Djemile ante la opinión pública internacional como el rostro de la revolución argelina.

${ }^{38}$ VERGÈS, J., Op. cit., p. 38. 
Con esta estrategia de ruptura, Jacques Vergès trató de conseguir que la opinión pública internacional se interesara por el juicio, empatizase con los defendidos, para lo que alargó al máximo el mismo hasta que se produjese un cambio político que beneficiase a sus clientes. Vergès consiguió así que la condena a muerte a la que la propia Djemile fue condenada por el Tribunal se conmutara por una cadena perpetua de trabajos forzados que no sería cumplida porque los Acuerdos de Erian de 1962 que pusieron fin a la Guerra de Argelia establecían una serie de medidas de amnistía de las que se benefició la propia Djemila.

Esta estrategia de ruptura mediante la cual Vergès opone al acusado contra el sistema judicial dio lugar a que se le conociera como el "abogado del diablo" o el "abogado del terror" 39 , y tuvo su máxima exposición en la defensa que hizo del teniente nazi Klaus Barbie.

Klaus Barbie, de origen alemán, se integró en 1935 en la GESTAPO y fue trasladado en 1942 a Lyon como jefe local de la GESTAPO, donde le dieron el apodo de "el carnicero de Lyon". Entre los crímenes más graves de los que se le acusaba se encontraba la captura de 44 niños judíos de un orfanato en Izieu y su deportación a Auschwitz; la captura, tortura y muerte de Jean Moulin, miembro de la resistencia francesa detenido por los nazis; y la deportación a Auschwitz de 650 franceses el día 11 de agosto de 1944 en el último convoy de deportados.

Vergès asumió en solitario la defensa del teniente nazi acusado frente a los cerca de 40 letrados de la acusación. En su alegato final Vergès se presentó solo, sin el acusado, acompañado de dos letrados: uno negro (Martín Mebella, congolés) y el otro magrebí (Die Nabil Bovaïta, argelino). De este modo, todas las miradas se centraron en los tres que aparecían como acusados de crímenes del nazismo por un amplio grupo de abogados de raza blanca. En su alegato, Vergès realizó una defensa del racismo, del antisemitismo, del infanticidio y de los franceses muertos en la resistencia y trasladó a su defendido sus virtudes y sus honores, pues su cliente había participado en la guerra combatiendo en África, en Italia y en Francia. Vergès, más que ningún otro abogado, reclamó su derecho a hablar en el juicio a favor de la Resistencia francesa.

La cuestión retórica que Vergès planteó en el juicio es la siguiente: ¿Qué delitos son los que se imputan a Barbie: crímenes de guerra o crímenes contra la humanidad? Si son crímenes de guerra estarían prescritos dado que el General De Gaulle había permitido la acusación contra Barbie en 1944 y

\footnotetext{
${ }^{39}$ Vid. http://www.youtube.com/watch?v=voU62pltZ1de.
} 
habría sido juzgado en rebeldía en Francia y condenado. Si, al contrario, son crímenes contra la humanidad, la cuestión que planteaba era si resultaba correcto aplicar unas leyes penales creadas para los juicios de Núremberg con carácter retroactivo al momento en que fueron promulgadas. Es decir: ¿es posible juzgar con leyes modernas comportamientos legalmente correctos en el momento en que se cometieron?

En el juicio de Barbie, lo que se juzgaba eran crímenes cometidos por soldados de otro pueblo distinto del francés, el alemán, en un periodo histórico en el que la sociedad alemana estaba impregnada de forma mayoritaria por la ideología nacional socialista. De este modo, los franceses estarían juzgando de acuerdo con sus valores que dicha ideología no sólo es incorrecta, sino criminal, y lo harían juzgando a sus figuras más destacadas de acuerdo a las normas externas a las del pueblo alemán promulgadas con posterioridad a la caída del régimen nazi.

En este punto, Vergès recordó a los abogados de la acusación ( $\mathrm{y}$ a la sociedad francesa que seguía el juicio a través de los medios de comunicación), que en Francia prendió la llama del colonialismo y que se cometieron crímenes similares a los cometidos por los nazis por los franceses en las colonias africanas $^{40}$. La estrategia de Vergès era clara: si se aplicaba la categoría de crímenes contra la humanidad a los hechos que se le imputaban a Barbie, se debería utilizar el mismo criterio contra los crímenes y abusos cometidos por los franceses durante la época colonial.

Lo que Vergès pretendía era hacer ver que existe una justicia de los vencedores, que son los que han detenido a Barbie y han preparado el caso contra él. De este modo, la noción de crímenes contra la humanidad es un "avión de bombardeo" hacia el pasado, en el que el vencedor se atribuye todos los valores humanos para prolongar su victoria. La humanidad no puede alegarse solo a favor del hombre blanco americano o europeo, sino a favor de todos los ciudadanos del planeta. Y como, de hecho, no sucede así, no puede hablarse de "crimenes contra la humanidad". Según este argumento, las leyes de Núremberg sólo tienen valor para el Tribunal de excepción que se constituyó en determinado momento histórico ante circunstancias históricas concretas que en el momento del juicio de Barbie ya no existían.

${ }^{40}$ Concretamente, en la construcción del ferrocarril en el Congo. La Societè de Construction des Batigmolles inició la construcción en 1921 del Chemin de Fer Congo-Ocean para comunicar entre sí, cruzando la selva, las ciudades del campo francés de Mbinda y Brazzaville y la ciudad portuaria de Pointe Noire. En dichos trabajos se utilizó mano de obra forzada del Chad y de la República Centroafricana y murieron alrededor de 17.000 personas; e, incluso, en la represión de Madagascar en 1947, donde las cifras de muertos por la represión francesa se aproximó a los 90.000 . 
En el segundo día de su alegato final, Vergès aludió a todas las irregularidades del proceso, al que llamó "mágico" (por la desaparición de la causa en el Juzgado varios meses, la existencia de un telegrama incriminador que era una fotocopia, etc.) y concluyó señalando que la violación de la legalidad es potencialmente tan seria como los crímenes contra la humanidad por los que era acusado Barbie.

Con este razonamiento, los fiscales y los abogados de la acusación pidieron el turno de palabra final que los Magistrados concedieron a pesar de la oposición de Vergès, de modo que la última palabra la tuvo la acusación y no la defensa.

Barbie fue condenado el 4 de julio de 1987 por crímenes contra la humanidad a cadena perpetua. Vergès aclaró que era consciente de que no podía ganar el juicio pero le dio un sentido diferente: oponerse a que el sistema francés olvidara sus propios crímenes coloniales.

La estrategia judicial de ruptura de Vergès nos lleva a cuestionarnos si todo vale en la retórica jurídica y el papel que juega la ética y la estética en su uso.

\section{EL DILEMA DE LA RETÓRICA JURÍDICA}

El dilema ético y estético que se plantea en la relación entre retórica y Derecho, a diferencia del discurso filosófico, por ejemplo, es que la retórica no tiene la pretensión de dar cuenta del ser de la cosa, sino del modo de presentarla, de la forma en que se construye discursivamente la existencia de un hecho, de la persuasión en un tercero de la realidad que se trata de ofrecer y, por lo tanto, la retórica jurídica no es sólo una técnica de argumentación, sino una forma de construir la verdad. Es una cuestión de estética, porque la retórica jurídica es arte, pero también de ética porque la retórica jurídica apunta al decoro, a lo apropiado, a lo adecuado. Paul Ricoeur señalaba que el arte de persuadir no sería distinto del arte de la mentira. Para el filósofo y antropólogo francés, la retórica constituye: "un uso frágil del lenguaje" porque se sitúa "a medio camino entre el nivel más elevado de la demostración racional y el argumento francamente sofisticado", entendido como un sofisma capaz de extorsionar a un auditorio ${ }^{41}$.

Es cierto que en la retórica jurídica existe una base de mentira que provoca un conflicto entre ética (entendido como lo moral) y estética (entendida como

\footnotetext{
${ }^{41}$ RICOEUR, P, “Lenguaje político y retórica” en Nueva Revista, 53 (1997) 158.
} 
el decoro, como lo apropiado, lo adecuado). Cuando Anito, Melito y Licon, acusaron a Sócrates de corruptor de jóvenes y sacrílego, persuadieron a 281 jueces de 556 sobre su culpabilidad. Más que a razones o argumentos, los tres sofistas apelaron a las emociones de los jueces para presentar a un Sócrates que arengaba a los jóvenes a que perturbaran las leyes de Atenas y a ser impíos con los dioses. Sin embargo, Sócrates, que precisamente rendía culto sagrado a los dioses y, además, predicaba la sumisión a las leyes de Atenas, llegó a preferir la muerte que las leyes atenienses le prescribían antes que la sublevación. Horas antes de morir advirtió que no siempre es la verdad la que suena agradable y persuasiva, ya que muchas veces la mentira se sirve con los mejores condimentos, haciendo de lo verdadero, insípido y reprobable, y de lo falso, agradable y creíble ${ }^{42}$.

La condena de Sócrates permite distinguir entre la capacidad del lenguaje para describir la verdad y su igual capacidad para persuadir. El lenguaje es un instrumento que recrea los hechos, pero a su vez los puede configurar a los intereses del emisor. Con el lenguaje se argumenta o se persuade, pero no siempre el que argumenta persuade, o el que persuade argumenta. Mientras que en la argumentación el criterio para determinar su validez o invalidez es su compromiso con la verdad, en la persuasión es la capacidad para adherir auditorios lo que define su corrección o incorrección. Otra vez, ética y estética, moral y arte en el Derecho.

El dilema que se plantea es evidente: ¿puede un discurso jurídico ser estético aunque no sea ético, aunque su base sea la mentira, la persuasión? Si la retórica es una técnica que se utiliza, que se enseña y se aprende, o que es innata al ser humano la pregunta surge desde el punto de vista moral: ¿es lícito usar una técnica empleada de forma estética para disuadir o convencer a un auditorio al margen de su consideración moral?

Es evidente que no se puede excluir ni negar la retórica en el Derecho, pero si es conveniente llamar a un uso humanístico de la misma. Este fue el propósito de Aristóteles, Cicerón y Quintiliano al establecer los límites de la retórica clásica. Para la retórica clásica, ya lo hemos apuntado, el decorum es lo que define la calidad de la persona del orador, de su ethos. Sin embargo, la dimensión esencialmente moral del orador difícilmente puede llevarse a la práctica porque, según decía Quintiliano, antes morir que faltar al decorum, lo que aplicado al Derecho conlleva una cierta tensión. Si un abogado ha de salvar su ethos para mantener el decorum: ¿cómo puede obrar para defender a un reo de una condena por un hecho que ha realizado? El dilema moral es

\footnotetext{
${ }^{42}$ PLATÓN, Apología de Sócrates.
} 
evidente: ¿es más importante para el orador mantener el decorum o salvar al acusado? Es más, ¿debería un defensor rechazar aquellas causas cuya defensa exige un empleo indecoroso de la retórica que lesiona la dignidad del orador?, ¿puede quedar ilesa la dignidad del defensor ante determinados reos? Llegados a este punto: ¿Habría acusados a los que no debería defender ningún jurista? Nada más lejos de la realidad. La misión del jurista es la de postular, en conciencia, la justicia, la defensa de los intereses y de los derechos de los particulares frente a la injusticia. Y en ello ha de valerse de los medios que legalmente son pertinentes al caso.

Para la nueva retórica, en cambio, lo esencial es la argumentación. Ahora bien, la argumentación es precisamente el tipo de razonamiento empleado por el jurista. Es en el discurso judicial donde más figuras retóricas se utilizan con la intención de convencer al juez cuando hay pruebas evidentes de ello. Si no las hay, habrá que persuadir al juez desde los indicios. Y si no hay pruebas ni indicios, habrá que seducir al juez desde el discurso retórico a fin de que se adhiera a las ideas propuestas mediante estrategias. En todo caso, la nueva retórica jurídica apela a la formación legal de un hombre bueno.

En este sentido, la nueva retórica jurídica debe ser entendida como aquellas operaciones sobre el lenguaje jurídico para construir un enunciado jurídico con intenciones argumentativas. Estas operaciones son realizadas por un orador que tiene por objeto crear estrategias discursivas para influir sobre el auditorio al que se dirige. Téngase en cuenta que en el proceso jurídico los hechos no son verdaderos o falsos, sino probados o no. Lo que se ofrece no es la verdad o la falsedad de los hechos, sino la creación discursiva de los hechos de una manera determinada y probada a la luz de los discursos, empleando estrategias discursivas para la construcción del enunciado jurídico mediante las técnicas y modelos de argumentación jurídica así como las acciones retóricas sobre el lenguaje.

Sin embargo, a pesar de su importancia, esta disciplina goza de desprestigio y de ser artificiosa y algo así como el arte en el que tienen su connatural asiento todo engaño, simulación y astucia. Decía el famoso abogado francés Jacques Isorni que no es infrecuente que en alguna reunión mundana, durante una cena, alguien se incline hacia un abogado y le diga, tras unos instantes de conversación y casi confidencialmente, como si se tratara de algo íntimo: ¿cómo puede usted pedir la absolución de un culpable? ${ }^{43}$

El conocido catedrático norteamericano de Derecho y antiguo decano de la Escuela de Derecho de Hofstra durante cuarenta y dos años, Monroe Henry

\footnotetext{
${ }^{43}$ ISORNI, J., Los casos de conciencia del abogado, Barcelona 1967, p. 11.
} 
Freedman (1928-2015), considerado "el pionero en el campo de la ética jurídica"44 y "uno de los principales expertos de la nación en ética legal"45 se preocupó mucho por la aparente distinción entre lo que es enseñado generalmente respecto a los deberes y ética del abogado frente a determinadas situaciones y las realidades de la conducta de quienes ejercen ${ }^{46}$. De sus numerosos trabajos y artículos publicados sobre la ética de los abogados merece destacarse uno especialmente relevante para nuestro propósito: "The Professional Responsibility of the Criminal Defense Lawyer: The Three Hardest Questions ${ }^{\prime \prime 47}$.

Freedman planteaba en ese trabajo las tres preguntas más difíciles que puede encontrarse el profesional del Derecho, aunque, en realidad, bajo esas cuestiones, lo que dejaba abierto era un abanico innumerable de dudas: ¿Puede el abogado hacer un interrogatorio de un testigo adversario a fin de desacreditarle o quitarle su credibilidad a sabiendas que el testigo ha relatado la verdad? ¿Ha de hacerlo o solamente para salvar a su cliente de un castigo? ¿Es compatible tal actuación con la probidad y la conciencia del abogado? ¿Se puede, honradamente, poner en duda el testimonio de otro, sabiendo que ese otro está atestiguando la verdad? ¿Debe el abogado compartir con su cliente esta falta de honradez? ¿Qué debe hacer el abogado frente al hecho de que su cliente le haya confesado su culpabilidad? ¿Puede insistir en la inocencia del acusado si éste le pide hacerlo? ¿Puede el abogado ofrecer un testigo a sabiendas de que éste va a perjurar?... ${ }^{48}$.

Estas cuestiones, y muchas otras que surgen del análisis de Freedman, ponen de relieve una cuestión: puesto que el abogado debe a su cliente una obligación primera, ¿puede esta obligación ceder y ser reemplazada por otra obligación superior de conciencia? Es decir, ¿esta obligación moral superior de conciencia le obligaría a apartarse de los intereses inmediatos del cliente subordinándolos a los requerimientos de este nuevo deber?

Es evidente que para el jurista honrado y con inquietudes existe realmente un agudo dilema profesional. El jurista tiene, además, el problema de iluminar el

${ }^{44}$ Vid. https://www.nytimes.com/1998/09/26/arts.

${ }^{45} \mathrm{Vid}$ https://www.theatlantic.com/doc/200809u/texas-execution.

${ }^{46}$ Entre sus libros deben destacarse: La ética de los abogados en un sistema adversario, publicado en 1975 y Comprender la ética de los abogados, publicado por primera vez en 1990.

${ }^{47}$ FREEDMAN, M. H., "The professional responsibility of the criminal defense lawyer: the three hardest questions", en Michigan Law Review, vol. 64 (1965/66) 1469. Ese artículo, debido al énfasis de Freedman en el deber del abogado de actuar como defensor del cliente incluso cuando el abogado cree que el cliente puede intentar mentir en el estrado provocó tal controversia que Warren E. Burger, entonces Presidente del Tribunal Supremo de los Estados Unidos, inició sin éxito un procedimiento de inhabilitación. Vid. TEMPLE, R. J., "Monroe Freedman and Legal Ethics: A Prophet in His Own Time" en The Journal of the Legal Profession vol. 13 (1988) 233-235.

${ }^{48}$ FREEDMAN, M. H., "The professional responsibility of the criminal defense lawyer: the three hardest questions" en Michigan Law Review, Vol. 64 (1965/66) 1467-84, en especial p. 1469. 
asunto de modo que sus interlocutores entiendan bien su planteamiento, pero el dilema no desaparece y de su solución satisfactoria depende la respuesta debida a la pregunta que encabeza el presente artículo. De este modo, mientras que un litigante no tiene que obedecer ni siquiera los preceptos de su propia conciencia en la conducción de su propio juicio, el que obra como defensor del juicio debe obediencia no sólo a su propia conciencia, sino a una superior de la que forma parte que encarna precisamente la Justicia. Hay, pues, una sutil distinción entre la deformación de los hechos del juicio y la información presentada al juez. Esta distinción clara, sin embargo, apenas percibida tiende a volverse confusa mediante la aplicación de las habilidades profesionales del abogado. Decía Ángel Osorio que, ante la opinión pública, el abogado es, precisamente, el que hace creer lo que no es, de otro modo, creíble ${ }^{49}$.

El arte del abogado, lo que éste le presta al cliente por sus honorarios, es la habilidad de ofrecer explicaciones convincentes y aceptables ante las autoridades que juzgan su causa valiéndose del empleo de la retórica jurídica y la estrategia judicial. Ahora bien, al exigir el cliente los servicios de un abogado ¿qué se le debe al cliente por su dinero? Desde luego, el cliente tiene derecho a un representante ante la Justicia que le sirve para decir todo lo que la ley le permitiría decir por sí mismo, pero utilizando las dotes de pleitear en una forma negada al lego por su falta de conocimientos y técnica forense. El régimen jurídico no le da al abogado ningún privilegio en virtud de su oficio para exceder los derechos del cliente: no puede decir más de lo que su cliente pudiera haber dicho por su propia cuenta. El abogado puede decirlo mejor con el adiestramiento y habilidad de su profesión, pero a él no le corresponde decidir si su cliente le ha mentido o no. Esta decisión corresponde al juez. Se refería Calamandrei al caso de aquel abogado que, habiéndose dado cuenta en la primera sesión informativa en que un cliente le exponía sus razones para un pleito que quería entablar, que el cliente le refería los hechos en forma totalmente distante de la verdad, y le interrumpió, sinceramente indignado, con estas palabras: "Caballero, hágame el favor; es preciso que cada uno haga su papel: Usted digame la verdad, que de decir las mentiras a los jueces ya me ocuparé yo" ${ }^{50}$.

Sin embargo, ni es cierto que la retórica aspire a mera palabrería y artificio, ni que la retórica sea el arte que enseña a amañar los argumentos para que, hábilmente dispuestos en discursos artísticamente adobados, se beneficien individuos arteros, taimados, ladinos y engañadores, pues la retórica no produce necesariamente, por ella misma, discursos de esa naturaleza, sino que se

\footnotetext{
${ }^{49}$ Vid. OSORIO, A., El alma de la toga, Buenos Aires 1940, p. 36.

${ }^{50}$ CALAMANDREI, P., Demasiados Abogados, Madrid 1926, pp. 75-76.
} 
mueve con mayor naturalidad y consigue mejor su objetivo, que es la persuasión, operando con argumentos verdaderos y nobles porque, como decía Aristóteles, lo verdadero y lo noble es siempre por naturaleza "más fácil de probar y más persuasivo" "51, ya que "lo verdadero y lo justo son siempre por naturaleza superiores a sus contrarios, de modo que si los veredictos no resultan como es debido, la derrota se debe necesariamente a los abogados en persona" ${ }^{~} 52$. Solo la retórica mal empleada como arte puede producir tan indeseables resultados, pero la culpa no será del arte de la retórica en sí misma, sino de quien usa mal de ella. Del mismo modo, se puede usar mal de bienes que son indiscutiblemente eso, es decir, cosas buenas por su propia esencia, como la fuerza, la salud o la riqueza ${ }^{53}$.

Desde el punto de vista estético, el arte de la retórica jurídica, manejado por un jurista inteligente, produce discursos sinceros y verdaderos, ya que es un arte que atiende fundamentalmente a pronunciar palabras honestas y hábilmente destinadas a un auditorio mediante la previa elaboración de argumentos verosímiles que constituyen su sustancia y nada es tan verosímil ni tan digno de confianza como la misma verdad y nada hay tan atractivo y seductor de los oyentes, ni tan fácil de probar como los mejores propósitos, intenciones y propuestas del orador cuando éste los expone noblemente, sin doblez, sintiéndolos de verdad.

Y desde una perspectiva ética, qué duda cabe, la retórica es el instrumento que posibilita al hombre el continuo ejercicio de la virtud. Al igual que el sacerdote y el médico, el abogado cumple una misión sagrada en la sociedad. Los tres son depositarios de la subjetividad más profunda de la persona. La conciencia íntima es el objeto que se entrega para que el sacerdote, el médico y el abogado asuman y dirijan el rumbo que debe tomar la vida del confidente por los caminos de la fe, la salud y el Derecho. Pero el asunto con el abogado se vuelve más relevante, porque el instrumento que utiliza para orientar es muy diferente de aquellos que disponen el sacerdote y el médico. En la confesión, el sacerdote escucha al penitente y, de acuerdo al lenguaje revelado por la divinidad, lo absuelve de sus culpas. El médico, por su parte, escucha al paciente, y luego, mediante la ciencia médica que construye a partir del conocimiento de las leyes de la naturaleza, le prescribe el tratamiento para su enfermedad. Pero el abogado debe escuchar a quien acude a él esperando obtener una respuesta desde el ordenamiento jurídico para materializar con la justicia una solución al problema que lo aqueja. A diferencia del sacerdote y el médico, el abogado no configura un

\footnotetext{
${ }^{51}$ ARISTÓTELES, Retórica, 1355 a 38.

52 Ídem, 1355 a 21.

53 Ídem, Retórica, 1355 b 41.
} 
lenguaje derivado de la revelación divina ni de las leyes de la naturaleza. El abogado tan sólo dispone del lenguaje jurídico, herramienta precaria contenida en las leyes, que se ve aquejada por las imperfecciones que generan la equivocidad, la vaguedad y la carga emotiva propia de los conflictos de intereses.

Por esto, la más noble de las profesiones puede llegar a convertirse en el más censurable de todos los oficios cuando la actuación no está orientada por la verdad, sino por la mentira ${ }^{54}$. Esto se nota cuando el estar, el hacer y el decir se utilizan como máscaras que tratan de representar hipócritamente con los vestidos de la justicia la más inhumana de las tragedias. Además, existe un inconveniente adicional: la aplicación del lenguaje jurídico depende de la voluntad de una persona, el juez, y muchas veces esta voluntad no está orientada por el abogado hacia la verdad. Y ésta es, pues, la angustia del abogado que, con un instrumento tan precario e imperfecto, debe responder a la confianza que en él se deposita.

El conocido juez del Tribunal Supremo británico Sir Malcolm Hilberry $(1883-1965)^{55}$, en un interesante libro sobre el deber y el arte de la abogacía, tras elogiar el honor de ésta, decía que, en la sociedad, quien tiene mayor conocimiento de las leyes y es su misión hacerlas respetar buscando las adecuadas aplicaciones de las mismas en los estrados judiciales, son los abogados a quienes reconoce ser poseedores de un honor y, por lo tanto, no deben tratar de ampararse en vericuetos legales que puedan brindarle impunidad frente a personas menos avezadas en las lides de la justicia, de modo que lo que a otros pudiera estar permitido por la ley, no lo está para el abogado si ello puede afectar a su honor y decoro ${ }^{56}$.

Sin embargo, cuando un cliente acude a un abogado lo hace porque, precisamente, cree que el letrado puede hacer lo que él mismo, sin esta ayuda

${ }^{54}$ Vid. la excelente selección de citas satíricas contra los abogados realizada por RECASENS SICHES, L., “¿Oficio noble o diabólico? Las antinomias de la profesión jurídica”, en Revista de la Facultad de Derecho de México, Tomo V, 1955 pp. 59-95, en especial, pp. 60-65.

${ }^{55}$ Presidió el juicio por el famoso asesinato de la actriz Eileen Isabella Ronnie Gibson, conocida profesionalmente como Gay Gibson, que desapareció durante la navegación de un barco entre Ciudad del Cabo (Sudáfrica) y Southampton (Inglaterra) en octubre de 1947. El caso fue conocido como "el asesinato del ojo de buey" porque el condenado por matarla admitió que había sacado su cuerpo del ojo de buey de su cabina en el Océano Atlántico. Afirmó que habían tenido relaciones sexuales consentidas y que ella había muerto de una aparente enfermedad repentina, se asustó y arrojó su cuerpo por la ventanilla de la cabina. Se han escrito varios libros sobre la muerte de Gibson. Vid, entre otros, BROWN, A. M. Muerte de una actriz: una historia real de sexo, mentiras y asesinatos en alta mar. Londres 2018; HERBSTEIN, D., El caso de asesinato en el ojo de buey: La muerte de Gay Gibson, Londres 1991; WILSON, C., Asesinatos en la década de 1940, Nueva York 1993.

${ }_{56}$ MALCOLM HILBERY, G., Duty and art in advocacy, Londres 1946, p. 8 y ss. 
profesional, no podría hacer. Es decir, convencer al tribunal mediante la retórica jurídica y la estrategia judicial de los méritos de su causa. Lo que espera el cliente es que el abogado supla con retórica jurídica aquello de lo que él carece. Y en esta tesitura el abogado se coloca en un dilema: Si se identifica con el asunto de su cliente, corre el riesgo de ser identificado por un público que no discrimina entre el supuesto malhechor y aquel al que defiende. Si no defiende con entusiasmo la causa del cliente, no sólo provoca la desconfianza de éste, sino que sus reservas pueden comunicarse a aquellos que están encargados del enjuiciamiento del asunto perjudicando de esta manera la suerte de su cliente.

El dilema que surge es evidente: ¿es honorable y aún moral luchar con todos los medios para conseguir un resultado que no está de acuerdo con las opiniones de la mayoría? Es evidente que la respuesta social es diferente a la jurídica. Lo que distingue al buen abogado de los demás es su entrenamiento profesional y esto es, precisamente, lo que le da el sentido de que su actitud moral está bien fundada ${ }^{57}$. Sin embargo, como en nuestra sociedad siempre están quienes no comparten la profesionalidad y tampoco las actitudes correspondientes, siempre habrá dos respuestas a la pregunta acerca de si un letrado puede servir a dos patrones: el cliente y la Justicia. Éste será siempre el dilema de la retórica jurídica, esto es, de qué manera el jurista puede emplear la retórica jurídica y la estrategia judicial como arte (estética) y también como virtud (ética) para que resplandezca la verdad y, con ella, la Justicia, sin afectar el decoro.

${ }^{57}$ Este dilema de conciencia y su solución están expuestos magistralmente por ISORNI, J., en Los casos de conciencia del abogado, Barcelona 1967, pp. 11 y ss. 